\title{
Discussion on main points on designing of instructional software
}

\author{
Jiujiu $Y u$ \\ College of Computer Engineering, Anhui SanLian University, 230601 Hefei, P. R. China
}

\begin{abstract}
Instructional software is a kind of software program or system, which reflects the teaching strategy according to the teaching objectives and teaching contents for the purpose on promoting teaching and learning by both computer technology and network technology. Firstly, the concept of instructional software, features and functions are introduced in the article. Secondly, making a detailed description on the current types of instructional software features for total eleven types, and discussing on main points on designing of instructional software for each type fully. Finally, an initial expectation on researches on directions of instructional software designing is given, which from three aspects on designing of teaching platform for SPOC(Small Private Online Course), designing of mobile learning resources, and the intelligence on designing of instructional software in the future.
\end{abstract}

\section{Introduction}

Instructional Software refers to the programs or software that is used in computer-assisted instruction, through the computer teaching content, structure, teachers teaching intent, guidance and control of teaching activities, to receive students' requirements and answers, storage of teaching materials for teaching and learning activities [1]. From the technical view, instructional software is a kind of computer software program that can display the teaching contents by displaying the text, sound, image, video, and other information media in an interactive way. From the perspective of content, the instructional software embodies the corresponding teaching strategy [1]. According to the teaching theory and the students' cognitive psychology, different instructional software has different characters and different ways of presentation. So, the main points on designing of different instructional software and its teaching purposes are also different.

\section{Classification on the instructional software}

\subsection{Demonstration type}

Instructional software of demonstration type refers to the teaching resources which introduce or show the content of teaching resources for the students. This kind of software is often designed by tools of PowerPoint, Authorware, Flash, and etc, with the text, pictures, animation and other forms of elements to display and explain the teaching content for students in multimedia classrooms of schools. The designing of instructional software for this type needs to follow some points:

\subsubsection{Concise and Highlights}

The present teaching of information on the page of software must be clear, and animation effect is not too much. Some additional effects which have nothing to do with the teaching contents, such as text, pictures, music and other information must be deleted.

\subsubsection{Information appropriate}

For the case of design of PPT, the words on each page cannot be too much, about 30 to 50 words are appropriate, and the quantities of concepts which transferred to students should not be more than five in one page.

\subsubsection{Clear structure and friendly interface}

The design on structure of the software should be provided with proper links between different pages, to display the content. Links for operation should be created on each page, and used to select the content of the presentation. Avoid redundant links and appearance of the page jump trek. The interface on software must be friendly, the contrast between background color and text on the pages should be strong and watched clearly for every student in classroom.

\subsubsection{Enhance the interactivity}

Corresponding author: yjjyjL@163.com

(C) The Authors, published by EDP Sciences. This is an open access article distributed under the terms of the Creative Commons Attribution License 4.0 (http://creativecommons.org/licenses/by/4.0/). 
The interactivity for software could be designed simply, the demo according to the preliminary design steps in the process of running are in turn. We suggest that appropriate increase interactivity can demonstrate problem sets in the link. For example, when students answer the questions correctly, the current page of software will be displayed the prompt information, the purpose of feedback on teaching information can be increased.

\subsection{Individual counselling type}

Instructional software of individual counselling type is based on method for individualized teaching, with the learning process of non-linear characteristics for learners. The learning content presented in the software does not divide the learning units into the chapters, but the content should be arranged from the learner's perspective. Learners can choose learning subject according to their own learning content. The designing of instructional software for this type needs to follow some points:

\subsubsection{Independent learning unit}

Each unit for contents of software should be have certain independence, and for different levels of students to learning, the sequence between each unit cannot be obviously.

\subsubsection{Individual guidance on teaching strategy}

The reasonable individual guidance on teaching strategy should be designed in software, and based on the knowledge points of context. The teaching strategy could be composed of a series of questions for testing. Through the test results of each student, it should be decided to let the students into the next phase of the learning process, or decided to the point for students to learning next.

\subsubsection{Control on learning process}

The control on learning process is the main body of students which is designed through the software for learning activities. For navigation buttons which are designed on pages of software to control page jumping. After a student finished a learning unit, the navigation can be used for summarizing the learning situation automatically. When the current unit is exit, at the same time, the following learning unit of content could be displayed for students automatically through the navigation by a decision strategy.

\subsection{Practice evaluation type}

Instructional software of practice evaluation type is focused on a particular course, and the main functions that designed are much simple. The main parts of software are composed of a lot of exercises for evaluation, and students could use the exercises to enhance their knowledge. The designing of instructional software for this type needs to follow some points:

\subsubsection{Setting types for exercises}

The type of exercises for testing are diversified, such as exercise types for choice, fills up the topic, true or false, and etc. At least two more types are included. The difficulty of the exercise should be reasonable, and the reference answer is needed to be provided also.

\subsubsection{Arithmetic on exercises selecting}

Random selection algorithm and adaptive selection algorithm are mainly included. Random selection algorithm is based on random selection on exercise, and suitable for evaluation for a large amount of students, but lack of pertinence. Adaptive selection algorithm is more targeted at one student, and suitable for the individual student's evaluation according to its own situation. The choice of exercise is more adaptability for a certain student through the software. Usually, the designer will select the corresponding algorithm according to users.

\subsubsection{Feedback mechanism}

Not only the function of evaluating for the software should be realized, but also the feedback mechanism needs to be designed. When the student finished exercises, the information for feedback should be displayed immediately, helping the student to know the result. The results of evaluating information include "right" or "wrong" for the answering. Some components of competition for participating could be designed in the software also, and the quiz show could be designed and realized between different students or between students and the computer.

\subsection{Teaching simulation type}

The main functions of instructional software of teaching simulation type is to using computer to simulate the phenomena on real world, using computer simulation technology or computer modeling techniques to show something of the structure and dynamics, to help students understand the changes in reality[2]. Students can observe phenomena on simulation by software, and to participate in the simulation process through playing a role in the process of simulation. Applications on this kind of software need to rely on professional virtual laboratory, the requirement on running for the software is not adaptable in ordinary classroom. The designing of instructional software for this type needs to follow some points:

\subsubsection{Simulation import}

Relatively, the instructional software for the type of teaching simulation is more complex about methods on using. Simulation import refers to displaying the background in the form of text or image to simulate for students before using the software, and the students could understand the transaction which is going to meet, 
the environment changes, for operation on equipments, etc.

\subsubsection{Scenarios simulation}

Scenario refers to the simulated objects at a particular time, by the time, place, characters and events. Usually, the scenario is characterized by a picture, or comes with $3 \mathrm{D}$ effect. Scenario simulation is refers to the software which is to simulated the above elements, and facilitate with students into the scenario as soon as possible, help them to understand the content for learning better.

\subsubsection{Situation interaction}

Situation interaction refers to the communication and information exchange between people and software interaction by the input/output devices of computer, such as request and response, etc. When a particular scene is presented by the software, students have to be responded in the scenario, and complete the corresponding operation. Operation type can be selected by projects or manipulation of the simulation objects, the reaction which is carried out on the events, etc. Of course, the content is decided by the function of the software which is provided.

\subsubsection{Feedback}

For instructional software, feedback refers to the system adjustment situation which is caused by the user action. That is to say, feedback is the correctness of the software to the user action degree of evaluation. For example, when the user's operation is error, the information such as "error, please ....." will be displayed to user automatically from the system with sound effects. Usually, feedback should be designed appropriate according to the teaching aim, teaching content and student's level from the software by designers.

\subsubsection{Simulation exit}

After a process of simulation finished, whether success or failure, the exit of the message must be designed to display for users. For example, displaying the message on encouraging user to continue or try again.

\subsection{Subject resource for exploration}

According to the specific teaching content and set up an opening website for teaching and learning. Usually, the instructional software of subject resource for exploration is in form of a website, and also be known as a specific website for learning. As a type of instructional software, the development direction of network learning is fully displayed to students. The main function of subject resource for exploration is connected with some special tasks for learning content, to inspire the students for exploring. Through active exploration on searching all kinds of the resources for learning and interaction with other students, the students could complete the task, to achieve the goal of learning [3]. The designing of instructional software for this type needs to follow some points:

\subsubsection{Topic selection on exploration}

The selection for topics on exploration should be extracted horizontal or vertical, according to the characters on teaching content which combined with the cognitive characteristics of students. The designing of topics can be based on chapter and section of textbook. And it also can be designed for appropriate extension of the content of the textbook, to form a topic which is comprehensive. Of course, the teacher can be allowed to design the topic interdisciplinary even, but the demands on capacities for students' learning are quite high.

\subsubsection{Task on exploration}

The task on exploration must have clear requirements. For the larger task, it should be broken into many subtasks. The goal of task design should be diversified, to have different goals and its evaluation criterion. In the process on the design of the task, the task is better to contained different profiles, and is advantageous for the division of cooperation, to achieve the goal of cooperative learning.

\subsubsection{Design on learning tool}

Exploration on learning is more depend on students' inquiry and collaborative communication, and it can't be departed from the support of learning tools. Students use the learning tools to complete the process on access to information resource, production and processing, to express their own thoughts, and communicate with others. So, the learning tools such as information searching tools (Baidu, Google), cooperative learning tools(BBS, WiKi, Message box), task statement tools(Word, Excel, PowerPoint) should be designed to integrate into the pages of software according to the purpose and content of the exploration on learning for the users.

\subsubsection{Design on evaluation}

During the process of the designing the exploration on subject resource, the way of the appropriate learning activity evaluation is need to designed according to the goal, task and the activities on learning, it play an important role to control quality for implementation on learning process. Learning process evaluation and result evaluation are included in evaluation, and the evaluation is constituted with self-evaluation, mutual evaluation between students and evaluation for teachers[1]. Teachers can set up the score ratio on each part in software according to the actual situation.

\subsection{Teaching game}


As a type of the instructional software, teaching game is in an independent existence for the development on the basis of the software of ordinary entertaining game. The essence of teaching games is computer software program yet, but the factors on interesting and competitive are added in the content for learning, to fulfilling the implied educational function for users. The teaching game is widely used in high schools and universities now. The designing of instructional software for this type needs to follow some points:

\subsubsection{The game object is duality}

The design of teaching object for teaching game is duality. On one hand, the teaching object is the object for the game itself, on the game player's perspective, the task of the game should be designed for completing the game levels. On the other hand, the learning object should be designed through the passing game levels for students too. That is to say, from the perspective of learners, when the students finish one level which is set by the teaching game, the learning object is able to achieve for the students.

\subsubsection{Scene space for the game}

Game scene space is the activities of the virtual world for players, and several factors should be designed for game scene space. Firstly, the background of the game should be designed accord to the teaching content, such as the style type for modeling of the characters in the game space, landscape, buildings and props. Secondly, the corresponding with learning information need to be embedded in the game, it can help students to master the learning content better. Thirdly, the cognitive tools for the teaching game is to be designed also, such as map, mobile way, dialogue, speech, and etc, as for the guiding direction to learning and application on feedback on learners' achievements.

\subsubsection{Rules of competition [4]}

Rules of competition are also referred to the rules of the game, the decisions and actions that taken by game participants must be complied with rules. Rules on competition are the real core of game designing. Teaching goal for students, teaching regularity and the knowledge should be included in rules of teaching game[4].From the perspective on computer programming technology, competition of the rules is the realization of the images of various mathematical models.

\subsubsection{Interaction}

The interaction with learners and computer should be designed to promote the operation of the game. On the basis of rules on human-computer interaction for designing on normal computer game, the designer for teaching game should according to learning content, and design the appropriate interaction. For example, how to use a mouse or keyboard for learning behavior operation by students in the process of the game, how to make use of information to answer questions in teaching game in order to promote game process, how to quit or continue learning process according to own intend, etc.

\subsubsection{Feedback and encourage}

Positive feedback need to be designed in teaching game, to make evaluation on a certain behavior or a periodic task for the player, and the game scenario should be changed also. The importance on feedback makes the players know their behavior is right or wrong, and to encouraging players to continue to make efforts on finishing the next task for the game. By the way, the form of information on feedback should be diversification. For example, using numbers to display the current player's score, using pictures to identify the player's current position in the game, using music to display the result(success or failure) for game mission, etc.

\subsection{Network course}

Network course is a certain subject for teaching contents with the implementation of teaching activities by network. The teaching aim, teaching content and teaching environment for network supporting are included in network course[5]. Teaching environment refers to the teaching platform for teaching activities, and many different courses could be based on one teaching platform. Now, the mainly teaching platform such as Moodle, Blackboard, 4A are widely used in universities of many countries. Of course, many teaching platforms with simple functions have been designed in many colleges and universities too, according to actual teaching environment, and to be implicated on teaching by network. Network course is the development on education of information period. The designing of instructional software for this type needs to follow some points:

\subsubsection{Design on learning object}

Learning object is E-learning resources for helping learners to complete a learning process, which is independent and complete. Learning instruction, content, practice and evaluation at least four parts are included in one learning object to provide a complete learning process for students. The particle size for a learning object should be designed appropriate. Usually, a unit such as a chapter or a section of the course could be designed as a learning object. By the way, a learning object should not be too easy or too complicated, and it should be designed independent and reuse.

\subsubsection{Design of learning resource}

The design of learning resource is the important part of the network course, and is closely related to the course content. Electronic courseware, case materials, all kinds of auxiliary teaching resource, exercises and etc are 
mainly included in learning resource. Every learning object should be corresponded to learning resource for supporting. Learning resource should be designed to have openness, diversity, independence and reuse.

\subsubsection{Strategies designing on self-learning}

Learners are the main body of the designing on network course. According to the actual environment of teaching and the characters for students, varied activities on selflearning strategies should be designed in network course, in order to stimulate the students to explore knowledge actively and positively.

\subsubsection{Design on evaluation}

In network course, after each learning unit, appropriate study effect on evaluation should be designed for learners, such as online testing, practice, homework, questionnaire survey and etc. The network teaching platform is to be able to provided measures for evaluation supporting, data analysis and statistics are also be provided for teachers according to specific format.

\subsection{Educational resource center}

Generally, education resource center is developed for a specific course, and refers to the course of mass education resources collection. Education resource center is convenient to learners for online browsing, searching and accessing the learning resource, and achieve the goal of learning. Usually, education resource is in the form of course website on the internet, teachers can release or update learning resource which related to the course, and students can login the website and download learning resource. For some course website, it also has modules for online testing, discussion, BBS, and other functions. The designing of instructional software for this type needs to follow some points:

\subsubsection{Privileges for four kinds of users}

Different from the normal website, the four kinds of privileges for users to login should be designed on course website. First, system administrator(assignment and management for all kinds of user privileges, course resources to add, modify, delete, and so on). Second, reviewing expert (from the perspective on teaching, scientific and normalization to review all kinds of new learning resources which was uploaded by teachers).Third, teachers and students(terminal users for the system, they can login the website to search and download the learning resources. But the teachers could upload the learning resources to website, and students do not have privileges to upload resources).

\subsubsection{Establish the service system as user-centered}

Educational resource center is based on website for the course, $\mathrm{B} / \mathrm{S}$ architecture is usually designed to establish the service system as user-centered. The front part of the system is the course website, and it is automatically generated according to the existing website templates. Page layout display technology is implicated on website, so the texts, pictures, tables and other elements in pages could be displayed beautiful. Educational resource center is the backstage of website in fact, and connected with the website by database system (SQL, DB2, Orcale). When Users (students or teachers) login the website, they can browse and search the learning resources conveniently, the operation is also simple for users. The information on update for the course will be automatically stored in the database, the system administrators can keep the course resources displaying on the website in time.

\subsubsection{Design on visualization of website templates}

The design process of the course site could be simplified by predefining the visual website template. Color templates and site layout templates are included in website templates, designers only need to provide course resources according to the actual teaching environment to apply the corresponding site template, and it is automatically generated website for the course, and simplifying the establishment of the website process.

\subsection{Network teaching platform}

The network teaching platform refers to the software system which is based on the Internet and provides the full support service for the network teaching. The network teaching platform is usually composed of the network teaching subsystem, the educational administration management subsystem, the network course collaborative development subsystem and the teaching resource management subsystem. At present, the development of functions on network teaching platform whatever domestic or abroad are relatively stable and mature. Various types of network teaching platform such as Blackboard, Moodle, Tsinghua Education Online, Nanjing Yi Xue sky and etcs are widely used in many domestic colleges and universities now. By contrast, it is much difficult to design of the network teaching platform, colleges and universities need to pay for installing and using. The designing of instructional software for this type needs to follow some points:

\subsubsection{Design of mobile learning}

Recently, mobile phone or other mobile device for online learning has become the mainstream of college students learning, and how to use the mobile device to finish the teaching process conveniently is also a popular topic of education research. Mobile devices must be able to access the network teaching platform successfully, and provide a variety of teaching services of network teaching platform for students. From the perspective on development on software, for the network teaching platform which based on $\mathrm{B} / \mathrm{S}$ architecture, how to 
integrate Mobile Learning Management System (MLMS) into business logic layer on network teaching platform and the variety of service is able to converted to mobile devices completely is one of the Main Points on Designing of network teaching platform.

\subsubsection{Collaborative development on network course}

Collaborative development on network course is the development trend of network course construction. First, the unified courseware development tools need to be integrated in platform, course resource and resource management software from the platform should be provided to teachers. So, it can simplify the burden of the resource collection when designing the web course. Second, It is necessary to design a unified network course template for the same course, and network course prototype files can be generated automatically through the template. It will bring convenience on course structure design, knowledge presentation and teaching design for teachers.

\subsection{Learning network community}

Learning network community is network space for learning in Web2.0 period, which based on social software such as Blog, WiKi, BBS, QQ and etc. Openness, equality, dynamic, beyond the boundaries of time and space are main characters on learning network community. User-centered, attention to the interaction of knowledge, sharing and collaboration, learners from the traditional passive learning knowledge into active access to knowledge are the main functions of learning network community. The designing of instructional software for this type needs to follow some points:

\subsubsection{Identity construction mechanism}

The mutual trust between learners is an important guarantee for learning process and communication in learning network community. It is necessary to design a perfect identity construction mechanism for learners. For example, real-name system mechanism is designed for registered learners that can bring advantages to carry out the equality and trust on education, reduce the speech which is not conducive for learning, and be more conducive to the expansion of the community.

\subsubsection{Mechanism on motivating users to participate}

It is important to design an effective mechanism on incentive users for participating the learning network community initiatively, and reward users to continue to participate in learning and discussion in community. For example, you can design score or point roll, for encouraging users to participate in posting, replying and other exchange discussion behaviors to get more scores, and increase the user's rank gradually to get more learning resources.

\subsection{MOOC platform}

MOOC(Massive Open Online Course) is a kind of online learning mode in the field of distance open education which is "learner-centered", and it is the product of educational idea fusion information technology in new situation. MOOC has emerged as an impact and opportunity of traditional universities [6]. As the mainly medium of open education, a strong support is provided by MOOC platform to carry out teaching activities for teachers. Since the three famous MOOC platforms (Coursera, Udacity and edX) which were opened from USA have been appeared by years of 2012, a strong development potent has been shown by MOOCs in the field of network teaching. More and more well-known domestic universities and educational management institutions are also active in developing the Chinese MOOC platform to promote work for distance education, such as Chinese Universities MOOCs, Cloud Class of Netease, Good University Online, and etc. It has the characters of large-scale learning (a large number of students) and open sharing (different regions, different backgrounds of registered learners can also share free teaching resources). The designing of instructional software for this type needs to follow some points:

\subsubsection{The presentation of the MOOC video}

Learning content and activities organization are the core elements of the MOOC, they are important factors which affect the learning process. Course video is the mainly way to present learning content in MOOC platform, and the learners can turn on different videos by navigating on the same page, reducing the distraction caused by populating multiple pages[7]. In addition, the completion of the states (Completed, Processing, Not start) should be marked during the process of video playing for different identification in order to improve the learners focus on learning and learning progress of self-control.

\subsubsection{The presentation of the MOOC forum}

Forum is the most frequent interactive tool for learners to achieve automatic posting subscription function in MOOC platform. From the view on ease of use, the topic list, discussion area and classification, sorting and other navigations should be designed in a page, which can reduce the jumping in different pages that caused by learning distraction[7]. In each of learning content and activity forum, the corresponding forum needs to be designed also. So, the learners can complete the targeted discussions, as well as a weekly discussion of the theme of the overall forum and public discussion area. In the end, a non-course content category of the forum which is classified by the MOOC platform should be set ahead atomically, without the manually setting by teachers.

\subsubsection{Peer review mechanism}

There are so many learners for online learning in MOOC platform, that the homework or exercise can not be 
assessed by a few teachers, the efficient peer evaluation mechanism need to be designed. A learner's homework is randomly assigned to another learner evaluation, and the process should be justice [8]. This requirement should be provided from MOOC platform, and to achieve thousands of learners to complete the evaluation function of peer review.

\section{Future researches}

With the development on educational information, on the current background of big data, mobile cloud and so on, the research on designing of instructional software needs to keep up with the pace on new technology in the future.

\subsection{Design of teaching platform for SPOC}

SPOC(Small Private Online Course) is the new development on web learning which is derivative of MOOC.SPOC is also the most important way for learning in Post-MOOC Era[9]. For small-scale learning crowd, focusing on campus localization, and to promote hybrid learning are the characters on SPOC. The teaching platform for SPOC can be a simplified design of the existing MOOC platforms, and is only applied on micro-curriculum construction. Colleges and universities can also design teaching platforms for hybrid teaching process which is based on SPOC concept according to the actual teaching environment.

\subsection{Design of resources for mobile learning}

With the popularity of $4 \mathrm{G}$ mobile networks, the learning by the using of mobile devices and wireless network has become the main learning methods. Mobile learning resources have the characters on simple interface, small and accurate of information content, and the design of interactivity, compatibility, applicability, and real-time on data transmission for various mobile client platforms (Android/Mac OS/Symbian) will be the trend on teaching software designing in the future [10].

\subsection{Intelligence on designing of instruction software}

With the development of teaching theory and artificial intelligence technology, especially the emergence of constructivism and Agent, learning activities have become a process of acquiring knowledge, including dialogue, situation, collaboration and meaning construction, and the direction of development on learning is to explore, cooperate and exchange on society. The design of Intelligent Tutoring System[11], Adaptive Hypermedia System(AHS), Interactive Learning Environment, Distributed Intelligent Learning System, and Educational Semantic Web will be the mainly directions for intelligent designing of instruction software in the future.
Author acknowledges financial support from the projects on teaching team of "Software Engineering course" of Anhui SanLian University (No. 15zlgc029) and "Massive Open Online Course on Software Engineering" of Anhui Province (No. 2015mooc104). Here, I would like to express my heartfelt gratitude to other colleagues from the both projects.

\section{References}

1. $\mathrm{Yu}$ Shengquan, The Handbook of Instructional Software Design, Beijing Tsinghua University Press, 2011.

2. Li Wenhao, Zheng Yan, Instructional Simulation: The New Approach in Integrating Technology in the Curriculum, Journal of modern educational technology, 2009, 16(4):9-12.

3. Yin Rui, Action Research on the Web-based and Problem-based Cooperative Learning Activity Design, Journal of modern educational technology, 2005,15(4) :34-39.

4. Wang Guangxin, Dong Fei,Summary of Educational Games Basic Structure and Character, Journal of China Educational Technology, 2009,(7) :77-80.

5. Wu Fati, The Principle of Objectives-Driven ELearning Course Design, Journal of China Educational Technology, 2006,(1) :17-20.

6. Cheng Zhu, LI Guilin, LIU Haitao,The Developments of Chinese MOOC Platforms,Journal of Higher Education Research, 2014,37(2) :15-16.

7. Wu Jinhui, Contrastive Analysis on Main MOOC Platforms in China, Journal of Library Work in Colleges and Universities,2015,35(1) :11-14.

8. Huang Ming, Liang $\mathrm{Xu}, \mathrm{Gu}$ Xiaolin, Mass Open Online Course-MOOC Overview,Beijing:Publishing House of Electronics Industry, 2015.

9. He Bin, CaoYang, SPOC: MOOC-based Innovation of Teaching Processes, Journal of China Educational Technology, 2015,(3) :22-27.

10. Li Lei,Li Xiaoli, Research on M-learning Resource Design Based on IOS Handheld Device, Journal of China Educational Technology, 2014,(12) :93-97.

11. Xu Gaopan, Zeng Wenhua, Huang Cuilan, Research on intelligent tutoring system, Journal of Application Research of Computers, 2009,26(11): 4019-4022.

\section{Acknowledgments}

